\title{
Plasmalemmal Insertion and Modification of Sodium Channels at the Nerve Growth Cone
}

\author{
M. R. Wood, ${ }^{1}$ J. DeBin, ${ }^{2}$ G. R. Strichartz, ${ }^{2}$ and K. H. Pfenninger ${ }^{1}$ \\ 'Department of Cellular and Structural Biology, University of Colorado School of Medicine, Denver, Colorado 80262 and \\ ${ }^{2}$ Anesthesia Research Laboratories, Brigham and Women's Hospital and Department of Biological Chemistry and \\ Molecular Pharmacology, Harvard Medical School, Boston, Massachusetts 02115
}

\begin{abstract}
We have characterized voltage-dependent sodium channels in growth cones (GCPs) isolated from fetal rat brain using saxitoxin and TTX binding as well as recordings from channels reconstituted into lipid bilayer membranes. Both highand low-affinity binding sites are present in GCP membranes. However, the two binding sites are segregated largely or completely, with the high-affinity binding sites in the plasmalemma, and the low-affinity sites in an internal membrane compartment. Plasmalemmal insertion of these internal sites can be triggered by high-potassium depolarization and depends on a metalloendoprotease-requiring mechanism. These observations indicate that a precursor-product relationship exists between the internal and external sodium channels of the growth cone, and therefore suggest that channel externalization causes conversion of low-affinity to high-affinity saxitoxin receptors. This conversion may represent a step of channel capacitation.
\end{abstract}

Transmission of electrical impulses in neurons is, in part, mediated by voltage-gated sodium channels in the plasmalemma. Each channel is composed of three polypeptide subunits $\left(\alpha, \beta_{1}\right.$, and $\beta_{2}$ ) produced in the rough endoplasmic reticulum and posttranslationally modified, that is, heavily glycosylated, in the Golgi (Hartshorne and Catterall, 1981; Messner and Catterall, 1985). However, the presence of a large pool of membraneassociated $\alpha$-subunits without $\beta_{2}$-subunits attached in neonatal rat brain in vivo suggests a delayed assemblage of the heterotrimeric glycoprotein complex (Schmidt et al., 1985). More recent evidence (Schmidt and Catterall, 1986) indicates that the association of the $\alpha$ - and $\beta_{2}$-subunits via a disulfide bridge takes place shortly before insertion into the plasmalemma (see also Wollner et al., 1988).

There is now a considerable body of evidence to show that the growth of neuronal processes is achieved by distal insertion of membrane at or close to the growing tip of the neurite (Bray, 1970, 1973; Pfenninger, 1982; Cheng and Reese, 1988). Pulsechase studies with lectin probes and a lipid label (Feldman et al., 1981; Pfenninger and Maylie-Pfenninger, 1981; Pfenninger and Johnson, 1983) have provided further support for this.

Received Jan. 7, 1991; revised Mar. 6, 1992; accepted Mar. 10, 1992

We thank Dr. Sherwood Hall for the generous donation of decarbamoylsaxitoxin and Dr. John Daly for providing the batrachotoxin. This research was supported by NIH Grants NS24676 (to K.H.P.) and GM15904 (to G.R.S.).

Correspondence should be addressed to Dr. Karl H. Pfenninger, Professor and Chairman, Department of Cellular and Structural Biology, Box B111, University of Colorado Heath Sciences Center, 4200 East 9th Avenue, Denver, CO 80262.

Copyright (C) 1992 Society for Neuroscience $0270-6474 / 92 / 122948-12 \$ 05.00 / 0$
These observations are consistent with the suggestion that the pool of large membrane vesicles, characteristic of the growth cone, is destined for plasmalemmal insertion (Pfenninger and Bunge, 1974; Lockerbie et al., 1991). The development of a technique for isolating membranes of neuronal growth cones (GCPs) from $18 \mathrm{~d}$ fetal rat brain (Pfenninger et al., 1983), combined with a method for maintaining GCPs intact and viable (Hyman and Pfenninger, 1985; see also Lockerbie et al., 1991), has enabled us to characterize $\mathrm{Na}^{+}$channels and to examine channel behavior during the process of plasmalemmal expansion at the growth cone. Although the GCP fraction is derived from many different neuron types, it is highly enriched in growth cones (Pfenninger et al., 1992), so fundamental processes, shared by most or all growth cones, can be investigated.

Specifically, this article addresses (1) the properties of the $\mathrm{Na}^{+}$ channels within isolated growth cones as defined by saxitoxin (STX) and TTX in binding studies and in conductance-blocking measurements after incorporation of the channels into black lipid membranes, (2) the compartmentalization of these channels within the growth cone, and (3) the insertion of the sodium channels into the plasmalemma.

Some of the data have been presented in abstract form previously (Wood et al., 1987, 1988, 1989).

\section{Materials and Methods}

\section{Growth cone isolation}

Growth cone particles (GCPs) were isolated from $18 \mathrm{~d}$ fetal rat brains according to procedures developed by Pfenninger et al. (1983). Four protease inhibitors were included in the homogenizing buffer for most of the toxin binding experiments: aprotinin [Trasylol, 100 kallikrein "inactivator" units/ml; Bayer Leverkusen, Germany, distributed by FBA, West Haven, CT], leupeptin $(1.0 \mu \mathrm{g} / \mathrm{ml}$; Sigma $)$, pepstatin A $(0.1 \mu \mathrm{g} /$ $\mathrm{ml}$; Sigma), and phenylmethylsulfonyl fluoride (PMSF) (0.1 mM; Sigma). The A-band at the load $/ 0.83 \mathrm{~m}$ sucrose interface of the discontinuous sucrose gradient contains the GCPs. Subsequent treatment depended on whether fragmented or intact GCPs were required.

\section{Fragmented GCPS}

The GCP fraction (A-band) was diluted with $0.32 \mathrm{M}$ sucrose buffer, and the GCPs were pelleted. Trituration in an appropriate buffer fragments the GCPs and exposes the internal membrane compartments. In STX/ TTX binding experiments, the buffer consisted of $100 \mathrm{~mm}$ choline chloride and $5 \mathrm{~mm}$ 3-[ $N$-morpholino]-propanesulfonic acid (MOPS) buffer; the $\mathrm{pH}$ was corrected to 7.2 with $\mathrm{KOH}\left(\mathrm{K}^{+}\right.$calculated to be $3 \mathrm{~mm}$ ).

\section{Intact GCPS}

The carefully diluted GCP fraction was loaded onto a $2 \mathrm{ml}$ cushion of Maxidens oil (Nycomed A/S, Oslo, Norway, distributed by Accurate Chemical and Scientific Corp., Westbury, NY; Hyman and Pfenninger, $1985)$. After centrifugation $\left(40,000 \times g_{\max }\right.$ for $\left.60 \mathrm{~min}\right)$, the GCP inter- 
faces were mixed with an equal volume $(\sim 200 \lambda)$ of essentially $2 \times$ modified Krebs' buffer consisting of $0.1 \mathrm{M}$ sucrose, $100 \mathrm{~mm} \mathrm{NaCl}, 10 \mathrm{~mm}$ $\mathrm{KCl}, 20 \mathrm{~mm}$ glucose, $44 \mathrm{~mm}$ HEPES, $2.4 \mathrm{mM} \mathrm{NaH}_{2} \mathrm{PO}_{4}, 1.2 \mathrm{~mm} \mathrm{MgCl}$, and $2.4 \mathrm{mM} \mathrm{CaCl}_{2}$. Each tube was rinsed with $1 \times$ modified Krebs' buffer consisting of $0.18 \mathrm{~m}$ sucrose, $50 \mathrm{~mm} \mathrm{NaCl}, 5 \mathrm{mM} \mathrm{KCl}, 10 \mathrm{~mm}$ glucose $22 \mathrm{~mm}$ HEPES, $1.2 \mathrm{~mm} \mathrm{NaH} \mathrm{PO}_{4}, 1.2 \mathrm{mM} \mathrm{MgCl}$, and $1.2 \mathrm{mM} \mathrm{CaCl}_{2}$. In both cases, the pH was adjusted to 7.4 with $\mathrm{NaOH}$. For those experiments in which high $\mathrm{K}^{+}$was used to depolarize the GCPs, the same modified Krebs' buffer mixture was prepared with a final concentration of $25 \mathrm{~mm} \mathrm{KCl}$ and a concomitant reduction in $\mathrm{NaCl}$.

\section{Synaptosome preparation}

Synaptosomes were prepared from adult rat cortices (Cohen et al., 1977) for comparison with GCPs.

\section{Toxin binding studies}

Saxitoxin (STX; Calbiochem, San Diego, CA) and tetrodotoxin (TTX; Sigma, St. Louis, MO) were used as probes for sodium channels. ${ }^{3} \mathrm{H}-$ STX was obtained from Amersham Corporation (Arlington Heights, IL). All of the binding studies were carried out on fresh GCPs and synaptosomes because freezing and thawing the GCP membranes reduces the amount of STX binding by $50 \%$ (M. R. Wood, and G. R Strichartz, unpublished observations). Centrifugation was used to separate the bound from the free toxin (e.g., Bennett, 1978; Bennett and Yamamura, 1985; Rogart, 1986). A time course of STX binding to fragmented GCPs in choline/MOPS buffer indicated that an equilibrium was reached after $2 \mathrm{hr}$ at $4^{\circ} \mathrm{C}$ (data not illustrated). Toxin and membranes were incubated in $1.5 \mathrm{ml}$ microcentrifuge tubes, usually in triplicate. Because the number of STX binding sites in these GCPs is low, relatively large amounts of fresh GCPs are necessary to obtain a significant binding signal. This is especially pertinent to the experiments with intact GCPs where only the plasmalemmal (i.e., exposed) sodium channels are measurable. We can fractionate for a single experiment a maximum of 150 fetal brains generating approximately $8 \mathrm{mg}$ (protein) of intact GCPs. Even this yield of fresh GCPs does not permit triplicate determinations at multiple toxin concentrations for both total and nonspecific binding under different experimental conditions. The incubation tubes were spun in a Beckman JA 18.1 rotor for $1 \mathrm{hr}$ at $18,000 \mathrm{rpm}(42,000 \times$ $\left.g_{\max }\right)$. A sample of each supernatant was removed to determine the free ${ }^{3} \mathrm{H}$-STX]. The surface of the pellet was rapidly rinsed with buffer and the tip of the centrifuge tubc cut off into a $7 \mathrm{ml}$ scintillation vial; each pellet was solubilized overnight at room temperature with $50 \mu \mathrm{l}$ of Protosol (New England Nuclear). Scintillation cocktail was added to each vial for counting in a Beckman LS1801 spectrometer. Unlabeled STX $(10.0$ and $1.0 \mu \mathrm{M})$ and, in some experiments, unlabeled TTX $(10.0$ and $1.0 \mu \mathrm{M}$ ) were used to determine nonspecific binding. Data were analyzed and plotted using either EBDA (Equilibrium Binding Data Analysis, Elsevier-BIOSOFT, Cambridge, United Kingdom) or GraphPAD Software, Inc., San Diego, CA.

\section{Blockade of neuronal sodium channels by saxitoxin}

The sensitivity of $\mathrm{Na}^{+}$channels in synaptosomes and GCPs to inhibition by the divalent cations STX and the STX derivative decarbamoylsaxitoxin (dcSTX) and by an (electrically neutral) uncharged STX homolog, $\mathrm{Cl}$, was assayed by the block of single channels incorporated into planar lipid bilayers (BLMs).

Bilaver channel reconstitution. BLMs were formed by painting across a $250-\mu \mathrm{m}$-diameter aperture in a polystyrene partition a solution of lipids in decane: 1-palmitoyl-2-oleoyl phosphatidylethanolamine: 1-palmitoyl-2-oleoyl phosphatidylcholine $(2: 1, w / w$; Avanti Polar Lipids, Birmingham, AL) at a total concentration of $30 \mu \mathrm{g}$ lipid $/ \mu \mathrm{l}$ decane. An aliquot of native membrane vesicles (ca. $100 \mu \mathrm{g}$ of protein in $0.32 \mathrm{~m}$ sucrose) was sonicated for $90 \mathrm{sec}$ and placed in the bath (designated cis). Channels were incorporated in BLMs with constant stirring and application of oscillating $( \pm) 50 \mathrm{mV}$ square wave pulses. An $\mathrm{NaCl}$ gradient across the bilayer ( $200 \mathrm{~mm} \mathrm{NaCl}$ cis, $50 \mathrm{~mm} \mathrm{NaCl}$ trans bath), used to enhance fusion rates, was collapsed prior to collecting data. Al experiments were performed in symmetric solutions of $200 \mathrm{~mm} \mathrm{NaCl}$, and $10 \mathrm{~mm}$ HEPES, and $200 \mu \mathrm{M}$ EGTA, at pH 7.40 .

Batrachotoxin (BTX; 200-400 nM from a stock solution dissolved in dimcthyl sulfoxide), obtained from Dr. J. Daly, Laboratory of Biorganic Chemistry, NIH, was added to the cis bath. STX, Cl, and dcSTX obtained from Dr. Sherwood Hall, FDA, Washington, DC, were added to the bath facing the naturally extracellular membrane surface to yield a final toxin concentration near the respective toxin's $K_{D}$ (see Tables 2 , 3). All work was performed at $21.5-23^{\circ} \mathrm{C}$. The possible contamination of $\mathrm{Cl}$ by its epimcrization product, GTX-2, was determined to be $<1 \%$ by the occurrence of long blocking events attributable to this toxin.

Channel recording. The cis and trans buffer baths were connected, via $1 \mathrm{M} \mathrm{KCl}: 1 \%$ agar salt bridges and $\mathrm{Ag} / \mathrm{AgCl}$ electrodes, to a List EPC-7 patch-clamp amplifier. Unfiltered data were stored in digital format on video tapes at a bandwidth of $40 \mathrm{kHz}$ for subsequent viewing and analysis, performed with an IBM-XT computer, using pCLAMP software, version 4.05 (Axon Instruments, Burlingame, CA) and a Labmaster A/D interface (Tekmar, Cleveland, $\mathrm{OH}$ ). Data from the video tape were filtered at $50 \mathrm{~Hz}$ low pass using a simple RC filter (KrohnHite model 3200, Andover, MA), and sampled at $50 \mathrm{~Hz}$ for computer analysis. A cutoff time, $t_{c}$, for the detection of blocking events was used in order to exclude the frequent brief closures characteristic of BTXactivated sodium channels (e.g., see Fig. 4, insets). For the analysis of STX data, only closures (blocking events) lasting longer than $1.0 \mathrm{sec}$ were accepted, while for the other dcSTX experiments a $t_{c}$ of $300 \mathrm{msec}$ was employed. The calculated mean dwell times were corrected for the use of these cutoffs as described by Moczydlowski (1986).

Calculation of blocking parameters. To calculate the kinetics of toxin blocking reactions, the mean open times and mean closed times from a continuous record were calculated and set equal to the inverse of the rate of binding and the rate of dissociation, respectively, of a bimolecular reaction (Krueger et al., 1983; Moczydlowski et al., 1984). That such kinetics are applicable here was shown by an independent analysis of the blocking action of dcSTX, for which the data on open and closed times were organized as probability density histograms and fit by single exponential functions (see Fig. 4; see also Colquhoun and Hawkes, 1984; Moczydlowski, 1986). The time constants for these respective histograms equal the inverse of the rates of binding and of dissociation of the toxin. When both methods of analysis were possible, the kinetic parameters calculated by the separate methods agreed within $20 \%$. For consistency, however, all data reported in the Results (Tables 2,3) derive from the calculation of the mean open and closed times, and not from fits to the histograms.

The on-rate constant for toxin binding $\left(k_{+1}\right)$ is obtained by dividing the blocking rate by the toxin concentration (Hille, 1975; Wagner and Ulbricht, 1975; Hahin and Strichartz, 1981; Moczydlowski et al., 1984, 1986). Rate constants thus calculated are independent of [STX] or [dcSTX], each of which varied over about one order of magnitude for the particular channel type (see Tables 2,3 , notes).

Equilibrium dissociation constants, $K_{D}$, were calculated from the average fractional closed time of the channel $(Y)$ at a particular toxin concentration, $[\mathrm{TX}]$, using the equation $K_{D}=[\mathrm{TX}](1-Y) / Y$. For a firstorder reaction, $K_{D}=k_{-1} / k_{+1}$; the ratio of the mean rate constants, calculated from the kinetic data, agreed well with the $K_{D}$ determined from the mean steady state occupancy, as just described.

The significance of the differences in equilibrium constants or rate constants between "sensitive" and "resistant" channels was analyzed by the Wilcoxon rank-sum test (White, 1952). Significance was established at $p<0.05$ (see Tables 2, 3). GCP Na${ }^{+}$channels were categorized as either resistant or sensitive by comparing their $K_{D}$ values to that obtained for (sensitive) synaptosome channels. Channels with $K_{D}$ values of $>3$ standard deviations beyond the mean synaptosomal $K_{n}$ value were considered to be resistant; otherwise, the GCP Na${ }^{+}$channels were categorized as sensitive.

\section{Protein and phospholipid determinations}

Most of the data in this study are expressed in terms of picomoles of toxin bound per unit of phospholipid phosphorus rather than per milligram of protein because many of the experiments have been done with intact GCPs containing a large amount of cytosolic protein, while others were performed on lysed GCPs. Expressing the data per unit of lipid permits direct comparisons between such experiments. Phospholipid phosphorus content was determined using a combination of the methods of Chen et al. (1956) and Ames and Dubin (1960), with modifications. Protein determinations were performed according to Lowry et al. (1951).

\section{Results}

Characterizing $\mathrm{Na}^{+}$channels on $\mathrm{GCPS}$ by ${ }^{3} \mathrm{H}-\mathrm{STX}$ binding Fragmented GCPs and, for comparison, synaptosomes were incubated with ${ }^{3} \mathrm{H}-\mathrm{STX}$ in choline/MOPS buffer. Under these 


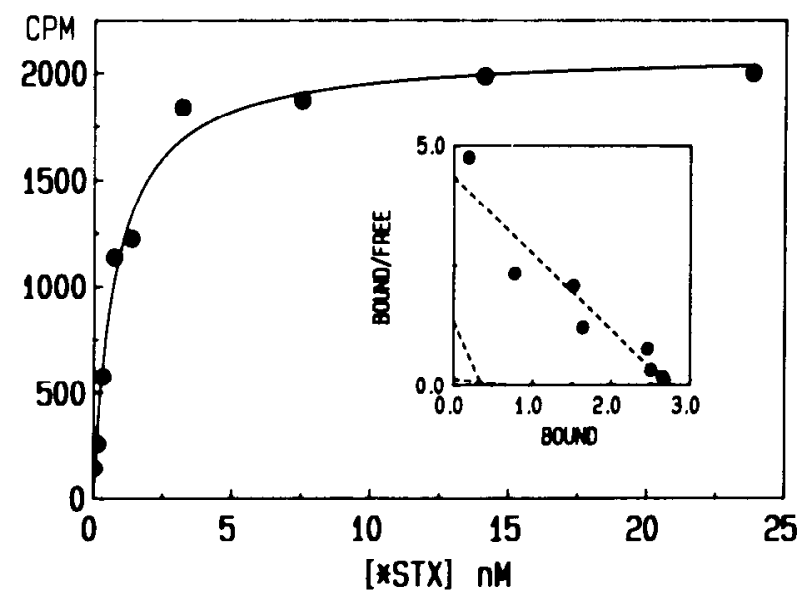

Figure 1. Specific binding curve of ${ }^{3} \mathrm{H}-\mathrm{STX}$ to fragmented synaptosomes (solid circles) in choline/MOPS buffer. The associated Scatchard plot (inset) defines a single binding site. The abscissa is picomoles bound/ $\mathrm{mg}$ of protein. For comparison, the regression lines (broken lines) for the GCP experiment illustrated in Figure $2 B$ have been superimposed on this graph.

conditions, the ligand has access to all membrane compartments and, therefore, to all binding sites in the two preparations. The data from these experiments are shown in Figures 1 and 2. The specific binding curve and associated Scatchard plot for synaptosomes shown for reference (Fig. 1) reveal a single highaffinity toxin binding site. The $K_{D}$ values from two separate experiments were 0.46 and $0.77 \mathrm{~nm}$. Figure 2 illustrates ${ }^{3} \mathrm{H}$-STX binding to fragmented GCPs under identical binding conditions. Figure $2 A$ shows data points for total, nonspecific, and specific binding. Nonspecific binding is considerably higher than for synaptosomes, contributing to data scatter (Fig. 6). The Scatchard plot of the specific binding curve in Figure $2 B$ is characteristically curvilinear (based on data from five experiments). This requires the presence of sites with two different affinities for STX binding. The $B_{\max }$ and $K_{D}$ values obtained from these experiments are listed in Table 1. GCPs have considerably fewer STX binding sites than synaptosomes. While their high-affinity site is similar or identical to the single binding site observed in synaptosomes, their low-affinity site appears unique.

The presence of TTX-resistant, STX binding sites has been reported in rat skeletal myoblasts and myotubes (e.g., Weiss and Horn, 1986a,b), sheep ventricular myocytes (Doyle and Winter, 1989), and frog sympathetic neurons (Jones, 1987). In view of this observation and of the fact that we used unlabeled TTX to define the nonspecific binding component in the above experiments, we conducted a series of competition binding studies
A

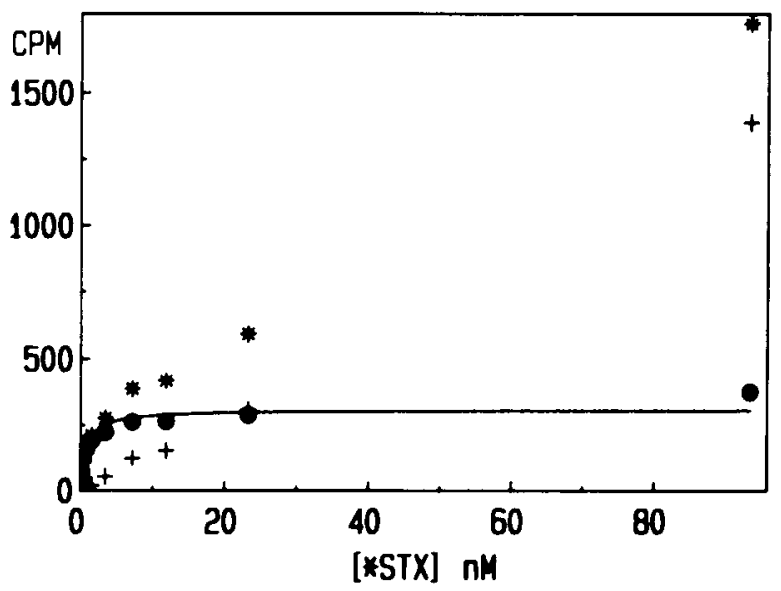

B

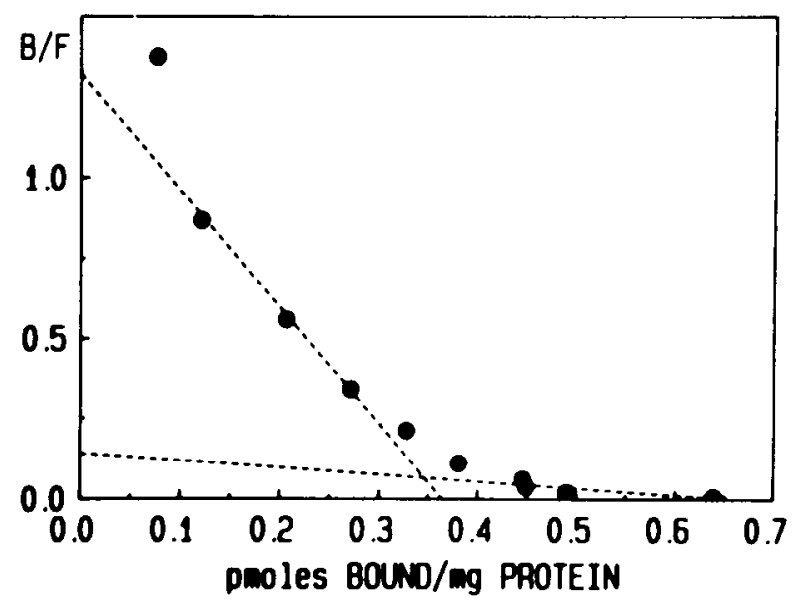

Figure 2. A, ${ }^{3} \mathrm{H}-\mathrm{STX}$ binding to fragmented GCPs in choline/MOPS buffer. Total $\left({ }^{*}\right)$, linear $(+)$, and specific binding (solid circles) data points are depicted with associated binding isotherm. $B$, The corresponding Scatchard plot for this experiment is curvilinear, and the regression lines depict a two-site fit; the regression line for the high-affinity site was determined by curve peeling of the data points. The abscissa is picomoles bound $/ \mathrm{mg}$ of protein. The $K_{D}$ and $B_{\max }$ values for these and associated experiments are summarized in Table 1.

to determine whether GCPs contained TTX-resistant STX binding sites. Since the GCPs appear to have both high- and low-affinity binding sites, competition binding studies were carried out using two different ${ }^{3} \mathrm{H}-\mathrm{STX}$ concentrations. Using 0.23 nM ${ }^{3} \mathrm{H}-\mathrm{STX}$ (Fig. $3 A$ ) and $2.0 \mathrm{nM}^{3} \mathrm{H}-\mathrm{STX}$ (Fig. $3 B$ ), displacement of the ${ }^{3} \mathrm{H}-\mathrm{STX}$ was achieved either by increasing concentrations of unlabeled TTX alone (solid circles with associated

Table 1. ${ }^{3} \mathrm{H}-\mathrm{STX}$ binding on fragmented GCPs and synaptosomes

\begin{tabular}{|c|c|c|c|c|c|}
\hline \multirow{2}{*}{$\overline{\text { GCPs }}$} & \multicolumn{3}{|c|}{$K_{D}$} & \multicolumn{2}{|r|}{$B_{\max }$} \\
\hline & High & $\begin{array}{l}0.38 \mathrm{nм} \\
0.28 \mathrm{~nm}\end{array}$ & $0.33 \mathrm{nM}$ & $\begin{array}{l}0.53 \\
0.37\end{array}$ & $0.45 \mathrm{pmol} / \mathrm{mg}$ protein \\
\hline & Low & $\begin{array}{l}3.38 \mathrm{nM} \\
4.65 \mathrm{nM}\end{array}$ & $4.0 \mathrm{nM}$ & $\begin{array}{l}0.85 \\
0.65\end{array}$ & $0.75 \mathrm{pmol} / \mathrm{mg}$ protein \\
\hline Synaptosomes & High & $\begin{array}{l}0.77 \mathrm{~nm} \\
0.46 \mathrm{~nm}\end{array}$ & $0.62 \mathrm{nM}$ & $\begin{array}{l}2.8 \\
1.9\end{array}$ & $2.35 \mathrm{pmol} / \mathrm{mg}$ protein \\
\hline
\end{tabular}


displacement curve) or, alternately, by maintaining the membranes in excess $(1.0 \mu \mathrm{M})$ unlabeled TTX and competing off any further specific binding with increasing concentrations of unlabeled STX (solid triangles). At both ${ }^{3} \mathrm{H}-\mathrm{STX}$ concentrations, there was no evidence for further displacement and, thus, for the presence of TTX-resistant STX binding sites in GCPs.

\section{Toxin blockade of channels incorporated into lipid bilayers}

Sodium channels from synaptosomes or GCPs can be reconstituted into lipid bilayers and activated by BTX. We found no discernible differences between the conductance of single channels from GCPs and synaptosomes (20-22 pS) which is close to the previously reported values $(22 \mathrm{pS})$ for mammalian brain $\mathrm{Na}^{+}$channels activated by BTX (Krueger et al., 1983; Green et al., 1987a). In both cases, the channel is open more than $90 \%$ of the time for membrane potentials positive to $-70 \mathrm{mV}$, and can be blocked for discrete periods by TTX and STX and its derivatives (Krueger et al., 1983). Two sample recordings of current through single channels exposed to dcSTX are shown in Figure 4 (insets in $A$ ). The durations of closed and open channel periods from many such events can be organized as probability density histograms, examples of which are shown in Figure 4, $A$ and $B$, and Figure $4, C$ and $D$, respectively. On the basis of such blocking kinetics, GCP $\mathrm{Na}^{+}$channels were classified as "resistant" or "sensitive" to STX and dcSTX, as described below. The fact that these histograms were well fit by single exponential functions confirms the first-order nature of the block of GCP channels by STX, which has been demonstrated previously for reconstituted brain and muscle $\mathrm{Na}^{+}$channels. These fits validate the use of the mean open time and mean closed time to calculate, respectively, $k_{+1}$ and $k_{-1}$ of the bimolecular toxin binding reactions (see Materials and Methods). The kinetic parameters, along with the equilibrium dissociation constants, $K_{D}$, determined independently from fractional closed times (see Materials and Methods), are listed in Table 2 for STX and in Table 3 for dcSTX.

Blockade of channels from synaptosomes was typically described (with one exception, see below) by one class of receptors that binds STX and dcSTX with high affinity $\left(K_{D}=0.57\right.$ and $2.35 \mathrm{nM}$, respectively, at $-50 \mathrm{mV}$ ). The lower affinity of dcSTX relative to STX is primarily due to its much faster dissociation rate; the on-rate constant for dcSTX is also slightly greater than STX's. Because of these differences, blocking and unblocking events occur more frequently with dcSTX, present at concentrations near its $K_{D}$, than with comparable relative concentrations of STX. The kinetic estimates with dcSTX are therefore more robust.

As reported previously, toxin binding affinities for BTX-activated $\mathrm{Na}^{+}$channels are vollage dependent (Krueger et al., 1983;
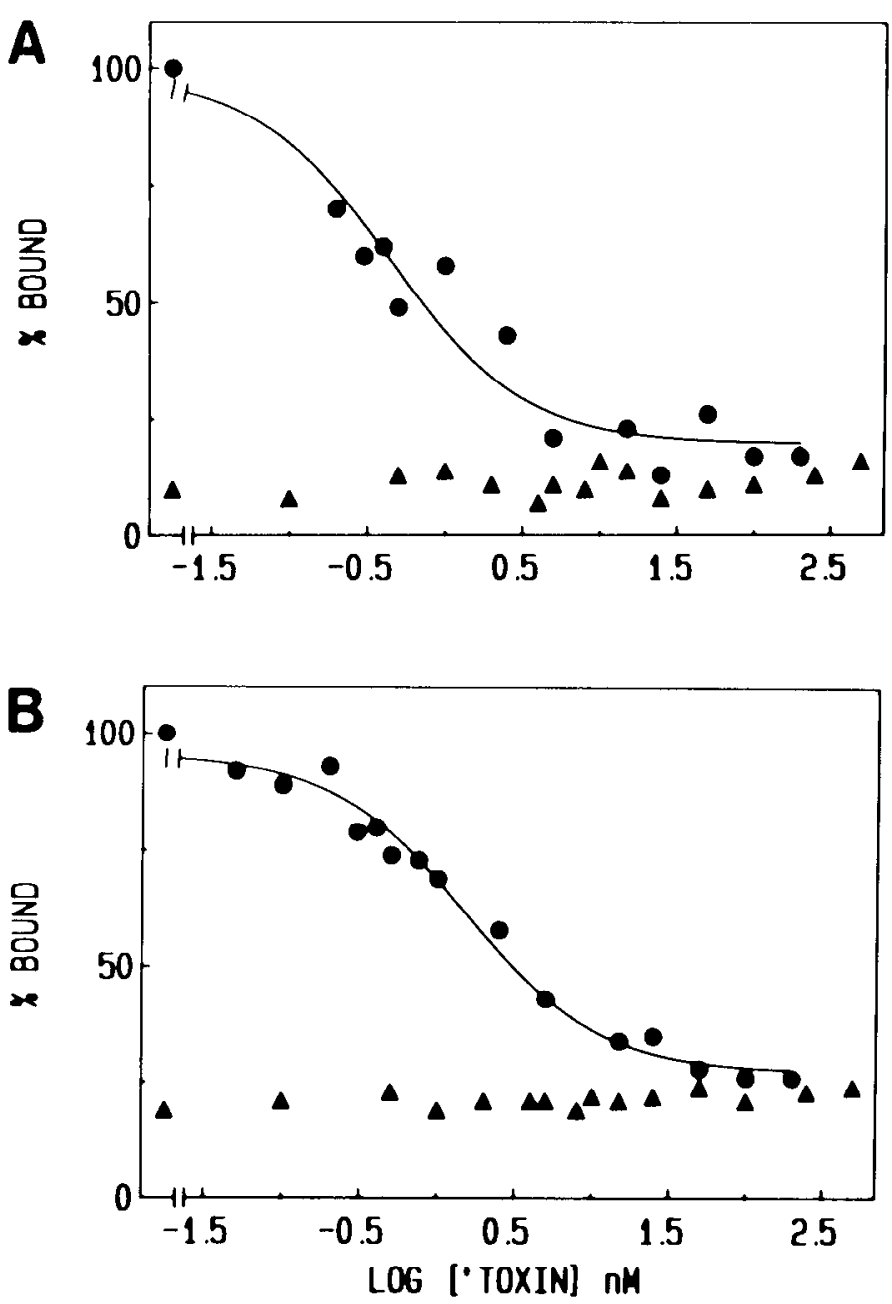

Figure 3. Displacement of $0.23 \mathrm{~nm}{ }^{3} \mathrm{H}-\mathrm{STX}(A)$ and $2.0 \mathrm{nM}{ }^{3} \mathrm{II}-\mathrm{STX}$ $(B)$ in fragmented GCPs using increasing concentrations of unlabeled TTX alone (solid circles with computer-generated curve) or increasing concentrations of unlabeled STX in the presence of $1.0 \mu \mathrm{M}$ unlabeled TTX (solid triangles). In $A$ and $B$, the $K_{i}$ values are $0.25 \mathrm{~nm}$ and 1.02 $\mathrm{nM}$, respectively. There is no evidence for TTX-resistant STX-binding sites.

Moczydlowski et al., 1984). The data in Tables 2 and 3 show that for depolarized channels at $+50 \mathrm{mV}$, the $K_{D}$ values are $15-$ 20 times greater than those for channels at $-50 \mathrm{mV}$; since $K_{D}$ $=k_{-1} / k_{+1}$, a factor of 3-4 is contributed by $k_{-1}$ to the voltage dependence of $K_{D}$ and a factor of about 5 by that of $k_{+1}$.

Very similar results are found for channels from GCPS, except that two binding classes are apparent in that preparation. One,

Table 2. STX blocking kinetics

\begin{tabular}{|c|c|c|c|c|c|c|}
\hline & \multicolumn{2}{|l|}{$K_{D}(\mathrm{nM})$} & \multicolumn{2}{|l|}{$k_{-1}\left(\sec ^{-1}\right)$} & \multicolumn{2}{|c|}{$k_{+1}\left(\times 10^{7} \mathrm{M}^{-1} \mathrm{sec}^{-1}\right)$} \\
\hline & $-50 \mathrm{mV}$ & $+50 \mathrm{mV}$ & $-50 \mathrm{mV}$ & $+50 \mathrm{mV}$ & $-50 \mathrm{mV}$ & $+50 \mathrm{mV}$ \\
\hline Synaptosomes & $0.57 \pm 0.15(9)$ & $7.31 \pm 1.98(6)$ & $0.042 \pm 0.008$ & $0.13 \pm 0.03$ & $7.73 \pm 2.10(9)$ & $1.85 \pm 0.72$ \\
\hline \multicolumn{7}{|l|}{ GCPs } \\
\hline Sensitive & $0.60 \pm 0.059(4)^{*}$ & $8.89 \pm 1.89(3)^{*}$ & $0.048 \pm 0.010(4)$ & $0.15 \pm 0.023$ & $8.14 \pm 0.77(4)^{*}$ & $1.82 \pm 0.030(3)^{*}$ \\
\hline Resistant & $1.85 \pm 0.77(4)^{*}$ & $23.74 \pm 6.69(5)^{*}$ & $0.047 \pm 0.013$ & $0.14 \pm 0.0042(5)$ & $2.5 \pm 0.94(4)^{*}$ & $0.64 \pm 0.33$ \\
\hline
\end{tabular}

Synaptosomes were studied using 1, 1.5, 2, or $11.5 \mathrm{~nm} \mathrm{STX;} \mathrm{GCPs} \mathrm{were} \mathrm{studied} \mathrm{using} \mathrm{1,} \mathrm{1.5,} \mathrm{5,} \mathrm{or} 31.5 \mathrm{~nm}$ STX. All data are mean \pm SD.

*, Significant at $p<0.05$; no mark, not significantly different, at $p>0.10$. Number of channels examined appears in parentheses. 

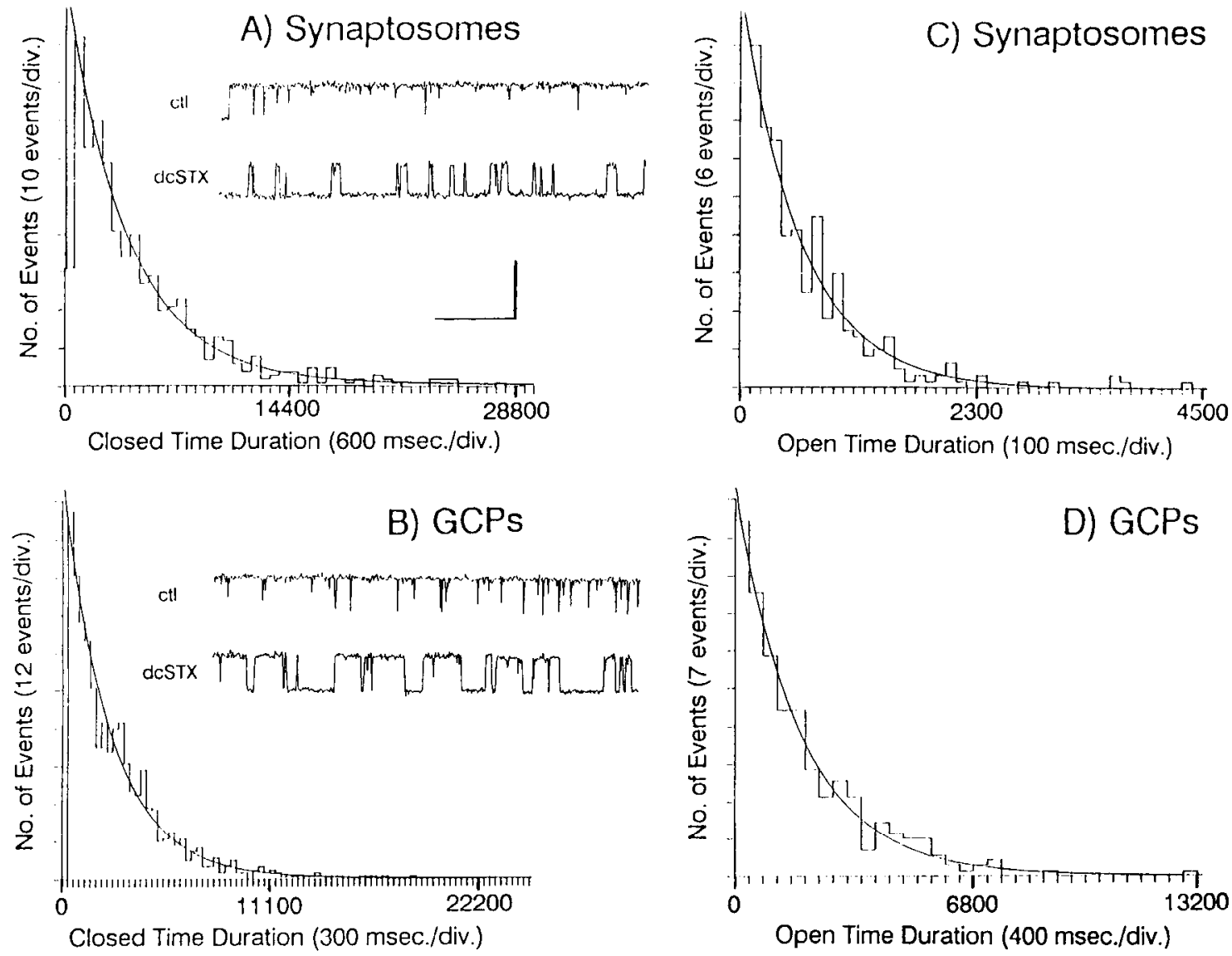

Figure 4. Probability density histograms of the open times (unblocked) and closed times (blocked) for dcSTX block of either synaptosomal Na channels $(A$ and $C)$, or "STX-resistant" GCP Na+ channels $(B$ and $D$ ). Each histogram was fit by a single exponential function from 0 msec on (in the case of the open duration histograms) or, to account for the use of $t_{c}$ of $300 \mathrm{msec}$ for the detection of closure, from $300 \mathrm{msec}$ on (in the case of the closed duration histograms; see Materials and Methods for details). Note the different $x$ - and $y$-axis scales in each panel. The membrane potential was $-50 \mathrm{mV}$ in all cases. $A$ presents the closed (blocked) time histogram obtained by compiling data from four channels (671 total events) blocked by 10-100 nM dcSTX. The time constant $\left(\tau_{b}\right)$ obtained from the exponcntial fit was 3969.9 msec, which agrces with the valuc of 4.44 scc for mean blocked time $\left(\tau_{k}\right)$ at $-50 \mathrm{mV} . B$ presents the closed time histogram derived from a compilation of data from six STX-resistant GCP Na ${ }^{+}$ channels ( 989 total events) blocked by $10-100 \mathrm{nM}$ dcSTX. The $\tau_{b}$ of $2541.6 \mathrm{msec}$ is close to the value of 2.94 sec obtained from current traces for mean blocked time. In $C$, the open (unblocked) duration histogram obtained from two synaptosomal $\mathrm{Na}^{+}$channels ( 367 events) blocked by 20 nM dcSTX is presented. As in $A$ and $B$, the time constant obtained from the exponential fit (583.4) is close to the value determined from mean open time (504 msec) in the presence of $20 \mathrm{~nm} \mathrm{dcSTX.} D$ displays the open time histogram for the block of three resident GCP channels ( 341 total events) by $10 \mathrm{~nm} \mathrm{dcSTX}$. The single exponential time constant, $1883.3 \mathrm{msec}$, is nearly identical to the value of 1.899 sec calculated for mean open dwell time $\left(t_{o}\right)$. The insets to $A$ and $B$ show examples of current traces from the respective types of $\mathrm{Na}^{+}$channel after exposure to either 20 nM dcSTX (synaptosomes) or $10 \mathrm{~nm} \mathrm{dcSTX} \mathrm{(GCP).} \mathrm{ctl.} \mathrm{Control.} \mathrm{Calibration} \mathrm{in} A$ is $2 \mathrm{pA}$ and $10 \mathrm{sec}$, and the open (unblocked) state is upward.

a high-affinity site, shows $K_{D}$ values at $-50 \mathrm{mV}$ for STX and dcSTX of $0.6 \mathrm{~nm}$ and $2.35 \mathrm{~nm}$, respectively, comparable to the typical channel from synaptosomes. The other shows affinities for either toxin that are threefold less than those of the high- affinity channel. When histograms of the affinities for channel blockage by dcSTX are compared (Fig. 5), the two populations are both clearly present in GCPs, yet the "low-affinity" sites are virtually absent in synaptosomes. This difference arises from a

Table 3. deSTX blocking kinetics

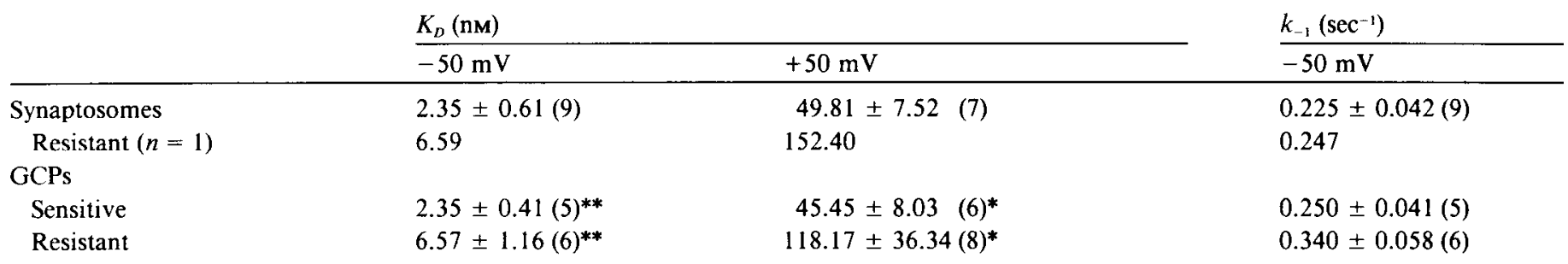

Synaptosomes were studied using 10-100 nM dcSTX; GCPs were studied using 25-100 nM dcSTX. All data are mean \pm SD.

*, Significant at $0.05<p<0.07$ between "sensitive" and "resistant"; **, significant difference with $p<0.05$ between "sensitive" and "resistant"; no mark indicates not significantly different, $p>0.10$. Number of channels examined appears in parentheses. 

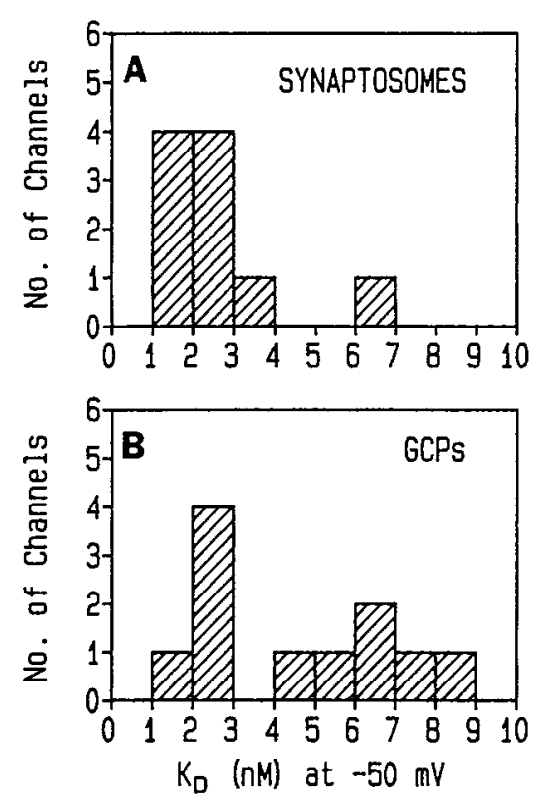
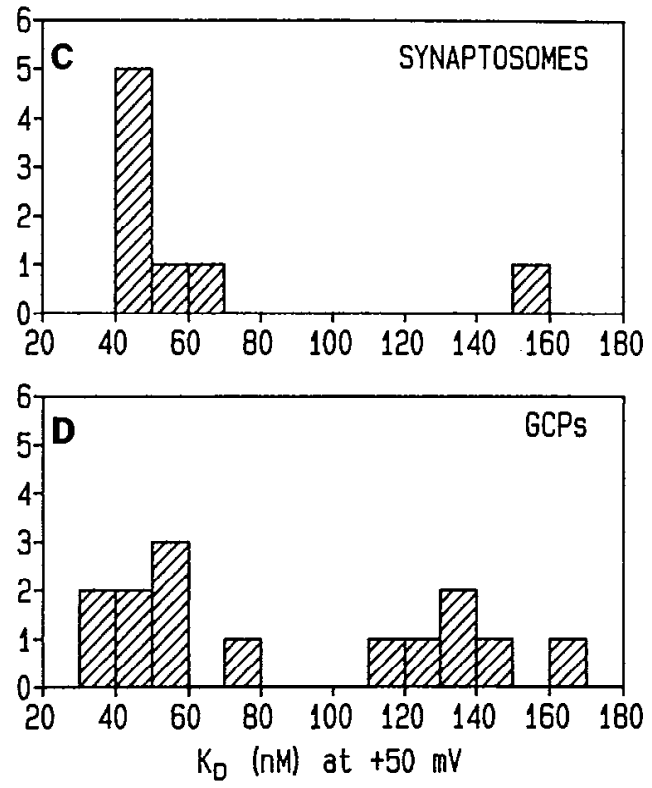

Figure 5. Histogram showing the sensitivity of $\mathrm{Na}$ channels reconstituted from synaptosomes $(A, C)$ and GCPs $(B, D)$ to inhibition by deSTX (100 nM) measured at $-50 \mathrm{mV}(A, B)$ or +50 $\mathrm{mV}(C, D)$. Equilibrium binding constants were calculated from mean block times and are distributed into $10-\mathrm{nm}$ wide bins. slower rate of binding in low-affinity channels; the dissociation rates are equivalent between the two types as attested by the significance values in Tables 2 and 3. "Sensitive" GCP channels were the same with respect to toxin block as those from synaptosomes (with the single noted synaptosomal exception), whereas "resistant" GCP channels had $K_{D}$ and $k_{+1}$ values nearly threefold higher than the respective mean synaptosomal values.

Because binding rate constants for STX are strongly dependent on the electrical charge of the toxin molecule (Moczydlowski et al., 1984), we also examined blockade of synaptosomal and $\mathrm{GCP} \mathrm{Na}{ }^{+}$channels by the toxin $\mathrm{Cl}$, a homologous saxitoxin that has no net charge, in contrast to the divalent cations STX and dcSTX. The actions of this molecule, summarized in Table 4 , are the same in GCPs and synaptosomes. Binding rate constants, in particular, were almost identical between the two sources of channels.

\section{Compartmentalization of binding sites}

The growth cone and GCPs both contain substantial quantities of membrane in distinct internal compartments such as smooth endoplasmic reticulum and, especially, large vesicular profiles. Since our data indicate that two types of STX binding sites are present in fragmented GCPs, the question arises whether the two binding sites are compartmentalized. STX binding studies were conducted on intact, sealed, and viable GCPs (cf. Lockerbie et al., 1991) to determine the properties of the STX binding sites on their plasmalemma. In order to maintain the integrity of the intact GCPs, the binding buffer was changed from choline/ MOPS, used in the STX binding studies described above, to either $0.32 \mathrm{M}$ sucrose/MOPS buffer or modified Krebs' buffer. Figure $6 A$ illustrates two Scatchard plots of STX binding in sucrose/MOPS to intact GCPs (open circles) and saponin-treated GCPs (solid circles). In the intact GCPs, a single high-affinity binding site is evident with a $K_{D}=0.54 \mathrm{~nm}$. Exposing the internal membrane compartments with saponin shows a curvilinear Scatchard plot indicative of a two-site fit. The high-affinity regression line is a product of curve peeling and shows a $K_{D}=$ $0.45 \mathrm{~nm}$. The low-affinity site has a $K_{D}=5.20 \mathrm{~nm}$ (cf. Figs. 1, 2; and Table 1).

For complementary competition binding studies, intact GCPs were divided into two groups; one group was maintained intact while the second group was intentionally fragmented by pelleting and resuspension. Sucrose/MOPS buffer was used in both groups. The data for these experiments are illustrated in Figure 6, $B$ and $C$. When a low concentration of ${ }^{3} \mathrm{H}-\mathrm{STX}(0.13 \mathrm{nM})$ was displaced from either intact or fragmented GCPs using unlabeled STX (Fig. $6 B$ ), the resulting curves are very similar, and the $K_{i}$ values are not significantly different (intact, $0.59 \mathrm{nM}$; fragmented, 0.43 $\mathrm{nm}$ ). Although the number of binding sites associated with fragmented GCPs appears somewhat lower, the difference is not

Table 3. Continued

\begin{tabular}{|c|c|c|}
\hline$k_{-1}\left(\sec ^{-1}\right)$ & $k_{+1}\left(10^{7} \mathrm{M}^{-1} \sec ^{-1}\right)$ & \\
\hline$+50 \mathrm{mV}$ & $-50 \mathrm{mV}$ & $+50 \mathrm{mV}$ \\
\hline $0.885 \pm 0.185(7)$ & $9.92 \pm 2.55(9)$ & $1.85 \pm 0.58$ \\
\hline 1.038 & 3.73 & 0.69 \\
\hline $0.938 \pm 0.151(6)$ & $10.74 \pm 1.43(5)^{* *}$ & $2.078 \pm 0.201(6)^{* *}$ \\
\hline $1.022 \pm 0.353(8)$ & $5.27 \pm 1.14(6)^{* *}$ & $0.908 \pm 0.303(8)^{* *}$ \\
\hline
\end{tabular}



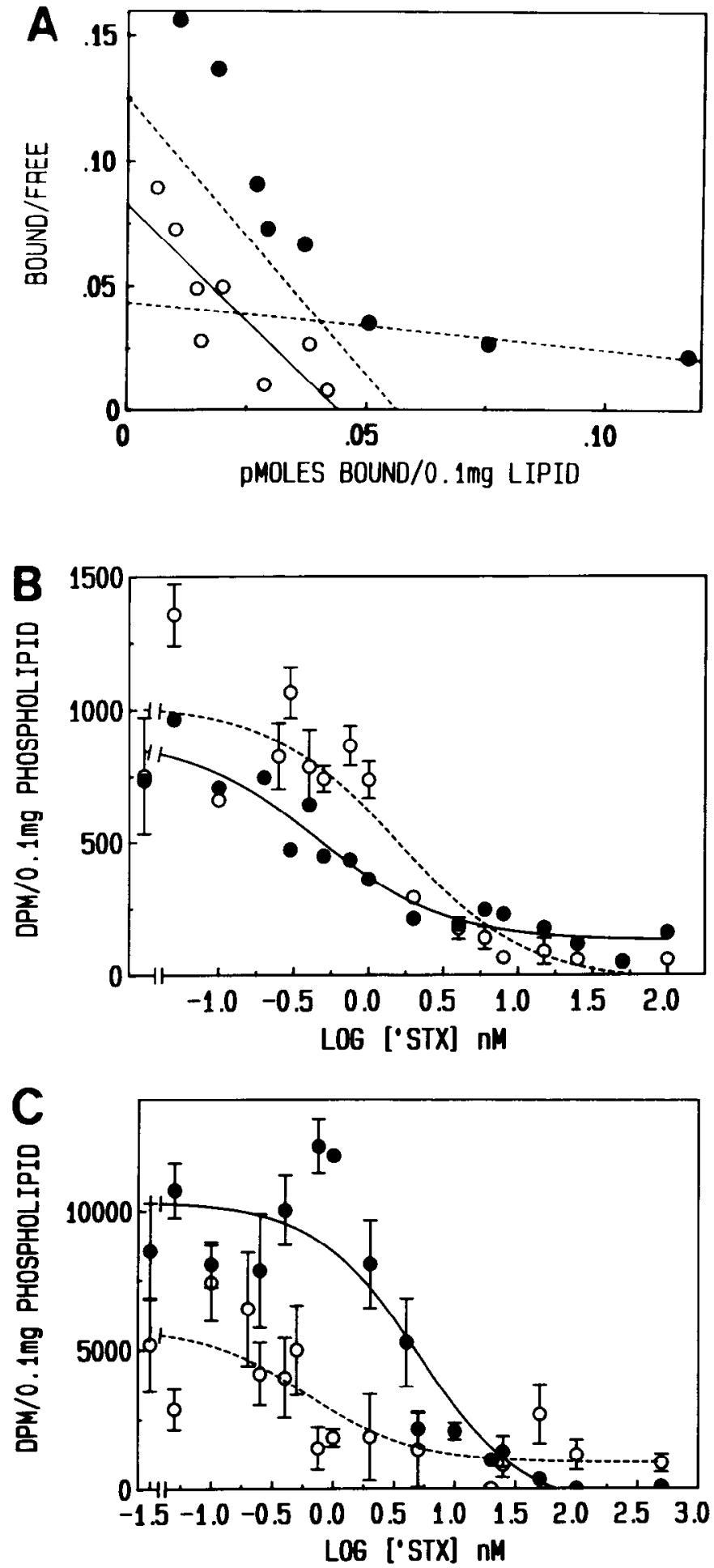

Figure 6. A, Saturation binding study on intact (open circles) and permeabilized (solid circles) GCPs (in $0.32 \mathrm{M}$ sucrose/MOPS buffer) to analyze the distribution of the STX receptors. Scatchard plot of the intact GCPs shows a single-site fit with a $K_{p}$ value of $0.54 \mathrm{~nm}$. However, upon treatment with $0.01 \%$ saponin, the Scatchard plot is curvilinear and defines a two-site fit; the high-affinity site has a $K_{p}$ value of 0.45 $\mathrm{nm}$, and the low-affinity site has a $K_{D}$ value of $5.20 \mathrm{~nm}$. The presence of only one binding site on intact GCPs is confirmed by competition binding studies below. $B$ and $C$, Displacement of $0.133 \mathrm{~nm}{ }^{3} \mathrm{H}-\mathrm{STX}(B)$ and $2.9 \mathrm{nM}{ }^{3} \mathrm{H}-\mathrm{STX}(C)$ from intact (open circles) and fragmented (solid circles) GCPs. In $B$, there is no displacement to the right or increase following fragmentation of the intact membranes (intact, $K_{i}=0.59 \mathrm{nM}$; fragmented, $K_{i}=0.43 \mathrm{~nm}$ ). (The data for the fragmented GCPs only are

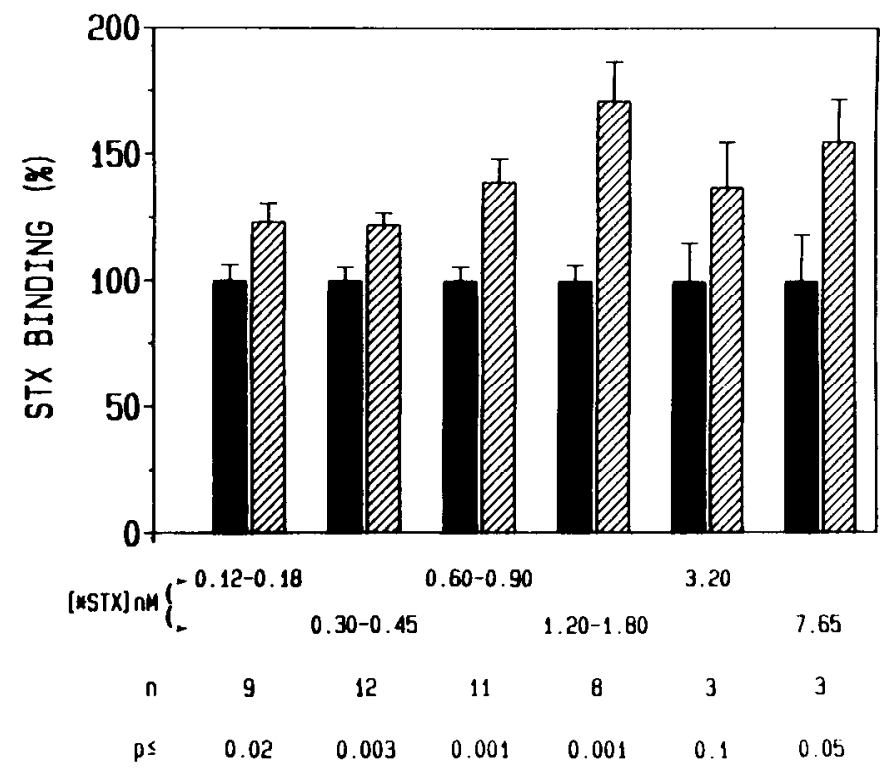

Figure 7. Histogram of the combined data from five scparatc experiments in which intact GCPs were treated with either regular (control) or high-K ${ }^{+}$Krebs' buffer followed by ${ }^{3} \mathrm{H}-\mathrm{STX}$ binding. Specific STX binding data were grouped into bins of increasing STX concentration from left to right $\left({ }^{*} S T X\right]$, in nM). The first four bins show data from a range of STX concentrations ( $n$, the number of measurements included in each bin) whereas the last two bins show data (triplicates) from single STX concentrations. The control values of specific STX binding in each bin were normalized to $100 \%$ (solid bars, \pm SEM) and the corresponding percentages calculated for high- $\mathrm{K}^{+}$treatment (hatched bars, \pm SEM). To test whether the increase in specific STX binding following high- $\mathrm{K}^{+}$ stimulation was statistically significant, Student's $t$ test was employed. The $p$ values (one tail) are shown below each bin. Note the significant increases in both high- and low-affinity STX binding sites on the GCP surface. In several of the experiments, STX mcasurcments were carried out in the presence of saponin, after control or high- $\mathrm{K}^{+}$incubation (data not shown, but see Fig. $8 B$ ): The values are very similar for a given STX concentration, indicating that high- $\mathrm{K}^{+}$treatment does not alter toxin binding, and they are considerably above those of nonpermeabilized GCPs (cf. Fig. 6), demonstrating that the GCPs remain intact. However high- $\mathrm{K}^{+}$treatment increases the ratio of superficially exposed versus total STX binding sites.

significant because it is small, and these points are derived from a single measurement. Upon using a higher ${ }^{3} \mathrm{H}-\mathrm{STX}$ concentration (2.9 nM), however, two major changes are evident (Fig. 6C). First, there is a marked increase in the amount of binding to the membranes following fragmentation, and second, fragmentation results in a shift to the right of the displacement curve, which is reflected in the $K_{i}$ values (intact, $0.36 \mathrm{nM}$; fragmented, $2.09 \mathrm{~nm}$ ). A similar result has been obtained using $0.01 \%$ saponin to permeabilize the intact GCPs (data not shown). It should be noted that saponin does not affect STX binding characteristics at this concentration, a fact established by lysing synaptosomes, resuspending them in sucrose/MOPS buffer, and measuring STX binding in the presence or absence of the detergent. Both experimental analyses of sodium channel distribution indicate independently that the two channel types are largely or

single points, whereas all other data points are means of triplicates \pm SEM.) $C$, in contrast, shows that there is a marked increase in the amount of STX binding and a significant shift to the right in the displacement curve following fragmentation (intact, $K_{i}=0.36 \mathrm{nM}$; fragmented, $K_{i}=$ $2.09 \mathrm{~nm})$ 
completely segregated, with the high-affinity sites on the outside and the low-affinity sites in a cytoplasmic compartment.

\section{Externalization of $S T X$ binding sites in GCPS}

Recent studies (Lockerbie et al., 1991) have demonstrated that depolarization-induced calcium influx into intact GCPs causes mobilization of WGA binding sites from an internal pool to the plasmalemma. This raises the question of whether the internal, low-affinity STX binding sites of GCPs can also be moved to the cell surface.

Intact GCPs were divided into two equal aliquots to which either modified Krebs' buffer containing high $\mathrm{K}^{+}(25 \mathrm{~mm})$ or, for the control, regular modified Krebs' buffer containing $5 \mathrm{~mm}$ $\mathrm{K}^{+}$was added while still on ice. Both preparations were then incubated in a water bath for $10 \mathrm{~min}$ at $37^{\circ} \mathrm{C}$. The GCPs were cooled on ice and, subsequently, ${ }^{3} \mathrm{H}-\mathrm{STX}$ binding was performed at $4^{\circ} \mathrm{C}$ for $1 \mathrm{hr}$ (see Materials and Methods). As a measure of the intactness of the GCPs, samples were also set aside and permeabilized with $0.01 \%$ saponin before STX binding. Because of the limited number of GCP samples that can be prepared and processed simultaneously, measurements can be performed at only three or four toxin concentrations in each saturation binding experiment. In order to allow for evaluation over a broader range of toxin concentrations and for statistical analysis, data from five separate experiments have been combined and are illustrated in Figure 7. The raw data (e.g., Fig. 8), consisting of $\mathrm{dpm} / 0.1 \mathrm{mg}$ phospholipid at different concentrations of ${ }^{3} \mathrm{H}$ STX, have been normalized, setting average binding for each control group to $100 \%$ and converting high- $\mathrm{K}^{+}$data accordingly. These percentage values were then grouped into bins covering a range in toxin concentration because the actual toxin concentrations vary to some degree from experiment to experiment. However, the last two bins in Figure 7 are from one cxperiment each, carried out at single toxin concentrations (triplicates). Statistical analysis was carried out using Student's $t$ test, and the $p$ values are tabulated below the histogram. At five of the six bins, a statistically significant increase in specific STX binding is observed following high- $\mathrm{K}^{+}$stimulation; at $3.20 \mathrm{~nm}$, the increase is only marginally significant, probably due to the limited number of data points. Thus, high-K' treatment increases significantly the number of externally exposed STX binding sites of both high and low affinity. In the presence of saponin, the high- $\mathrm{K}^{+}$and control samples exhibit very similar numbers of STX binding sites (data not shown in histogram). They are greatly increased over those of intact, control samples but only slightly above the numbers of plasmalemmal sites detected after high- $\mathrm{K}^{+}$treatment. While the high- $\mathrm{K}^{+}$effect is likely to be mediated through calcium influx (cf. Lockerbie et al., 1991), this has not becn established so far in these STX binding experiments because the calcium ionophore $\mathrm{A} 23187$ as well as changes in the external $\left[\mathrm{Ca}^{2+}\right]$ affect STX binding significantly (cf. Strichartz et al., 1986).
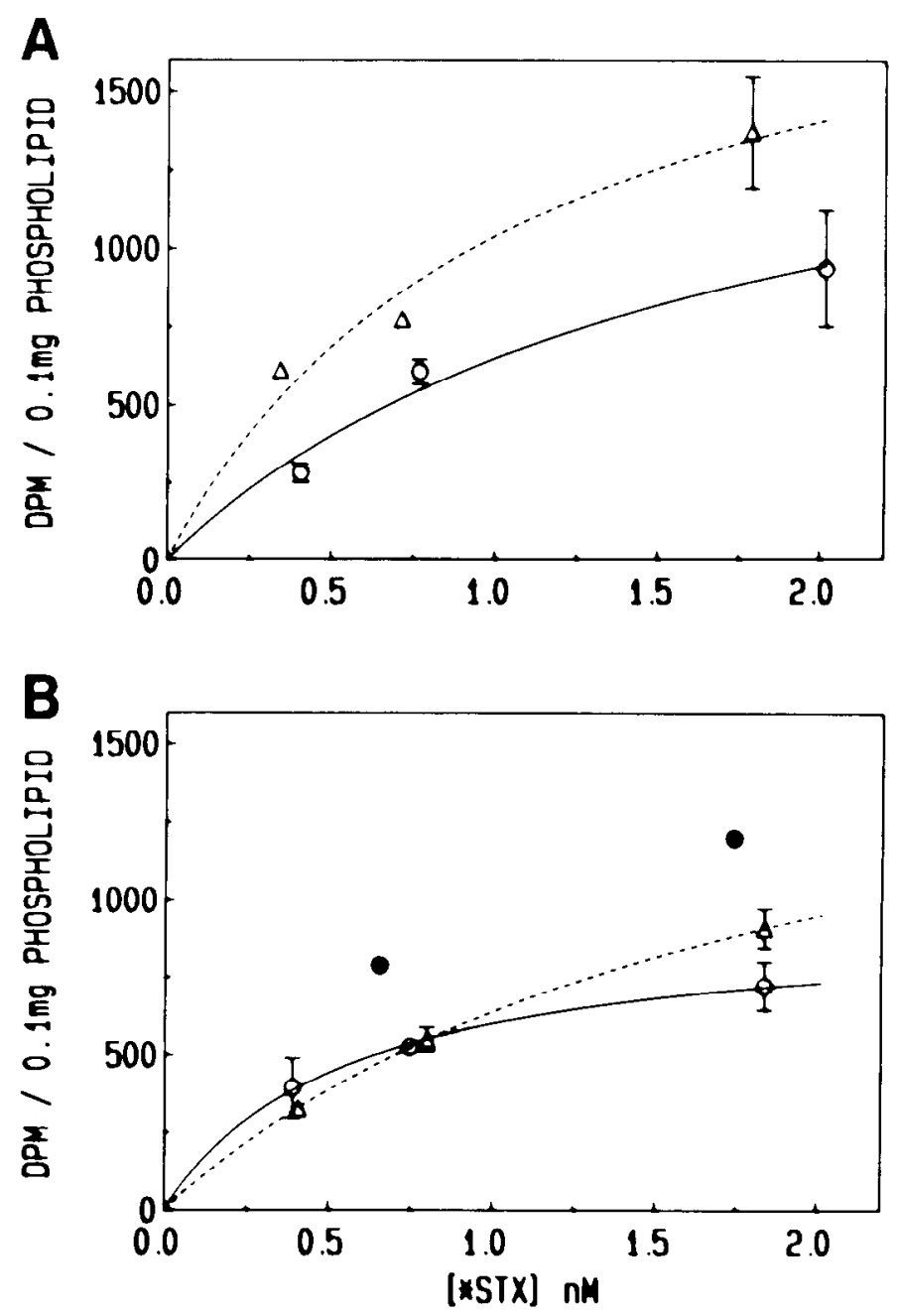

Figure $8 . \quad$ In $A$, high- $\mathrm{K}^{+}$stimulation (open triangles and broken curve), in the presence of aprotinin only increases specific binding relative to control (open circles and solid curve). However, the addition of a cocktail of protease inhibitors (aprotinin, leupeptin, pepstatin, and PMSF) blocks this high- $\mathrm{K}^{+}-$stimulated increase (open triangles and broken curve in $B$ ). Data points are means of pairs \pm SEM. The addition of $0.01 \%$ saponin to GCPs incubated in regular Krebs' buffer exposes all GCP binding sites (solid circles, single data points).

\section{Effect of protease inhibitors on the externalization process in GCPS}

Throughout most of the above STX binding studies, a cocktail of protease inhibitors (aprotinin, leupeptin, pepstatin, and PMSF) was used to preserve the integrity of the STX binding sites. In the presence of aprotinin only, externalization of STX binding sites does take place as described above. However, in the presence of all four protease inhibitors (freshly prepared), high-K ${ }^{+}$ incubation does not increase the specific binding of ${ }^{3} \mathrm{H}-\mathrm{STX}$ on

Table 4. STX blocking C1 kinetics

\begin{tabular}{llll} 
& $K_{D}(\mathrm{nM})$ & $k_{-1}\left(\mathrm{sec}^{-1}\right)$ & $k_{+1}\left(10^{7} \mathrm{M}^{-1} \mathrm{sec}^{-1}\right)$ \\
\hline Synaptosomes & $495.5 \pm 88.0(4)$ & $0.683 \pm 0.215(4)$ & $0.136 \pm 0.018(4)$ \\
GCPs & $540.7 \pm 157.5(7)$ & $0.836 \pm 0.235(7)$ & $0.155 \pm 0.018(7)$
\end{tabular}




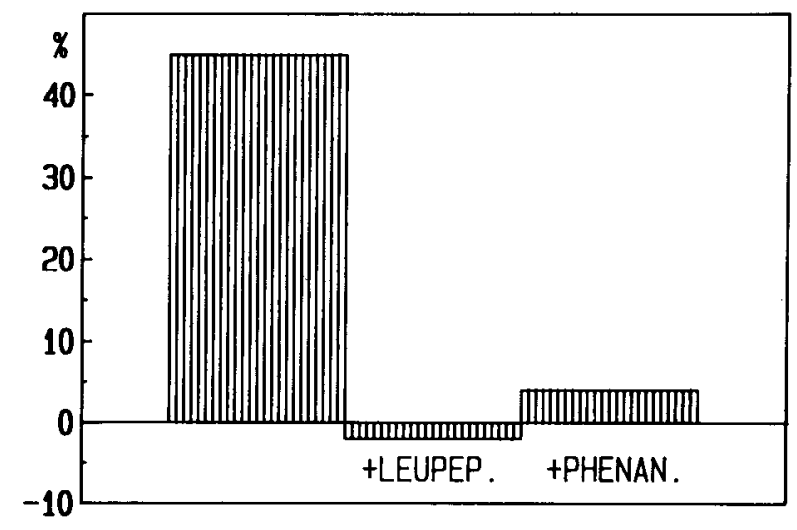

Figure 9. The effect of different protease inhibitors on $\mathrm{K}^{+}$-induced externalization of STX binding sites. The abscissa shows the percentage increase in exposed STX sites taken from the binding isotherms at 3.0 nM STX induced by high- $\mathrm{K}^{+}$stimulation. All samples contained aprotinin. The $>40 \%$ increase seen in the control (aprotinin only, left col $u m n$ ) is blocked by either leupeptin or 1,10-phenanthroline. (These results are averages from triplicate determinations.)

intact GCPs (Fig. 8A,B). Thus, there is no externalization of STX receptors, but the internal sites can be revealed following treatment with $0.01 \%$ saponin (solid circles, Fig. $8 B$ ).

In an attempt to determine which of the protease inhibitors could be influencing the externalization process, a parallel experiment was conducted in which fetal brains were homogenized with aprotinin alone, aprotinin with leupeptin $(2 \mu \mathrm{g} / \mathrm{ml})$, or aprotinin with 1,10 -phenanthroline $(1.0 \mathrm{~mm})$, each followed by STX binding. The graph in Figure 9 represents the depolarization-induced changes in specific STX binding (in percent) at 3.0 nм ${ }^{3} \mathrm{H}$-STX for each protease inhibitor treatment. The presence of either leupeptin or 1,10-phenanthroline reduces STX receptor insertion into the GCP plasmalemma significantly.

\section{Discussion}

The major observations reported here are the following. (1) GCPs, unlike synaptosomes, contain two forms of the sodium channel as defined by their STX association constants; the presence of a low-affinity STX binding site is specific to the GCPs. $B_{\max }$ values show almost twofold fewer STX binding sites in GCPs compared to synaptosomes. (2) In GCPs, the two types of STX binding sites are segregated largely or completely in two compartments; the high-affinity sites are found mainly on GCP plasmalemma and the low-affinity sites are prevalent in an internal membrane pool. (3) High- $\mathrm{K}^{+}$depolarization of intact GCPs increases the number of STX binding sites in the plasmalemma while total binding sites remain constant. (4) Certain protease inhibitors can compromise this insertion process.

\section{Two different $\mathrm{Na}^{+}$channels in growth cones}

Our observations of a singlc STX receptor site in synaptosomes, whether intact or lysed, are in agreement with previously published observations (e.g., Catterall et al., 1979; Krueger et al., 1979; Baumgold et al., 1983). STX binding to fragmented GCPs reveals significantly fewer binding sites compared to fragmented synaptosomes (cf. Scheinman et al., 1989). More importantly, our binding studies show not only a high-affinity STX binding site, with a $K_{D}$ value similar to that of the synaptosomes, but also a second, low-affinity binding site. Data from intact GCPs show that the high-affinity sites are located on the plasmalemma, and that the low-affinity sites are in an internal membrane compartment(s). Small numbers of high- and low-affinity ST X sites may actually be present in cytoplasmic membranes and plasmalcmma, respectivcly, but arc not measurable by either of the two assays used. Therefore, segregation of channel types must be nearly complete. This observation also argues strongly against heterogeneity of the GCP fraction as the explanation for the two binding sites.

Blockade by STX and dcSTX of BTX-activated $\mathrm{Na}^{+}$channels in planar bilayers confirms the coupling of both high- and lowaffinity sites to functional channels. Paralleling the binding data, both high- and low-affinity blockade was detected in this preparation, whereas essentially only the high-affinity block was seen with synaptosomes. Furthermore, the relative potencies of dcSTX to STX are like those reported for other $\mathrm{Na}^{+}$channels incorporated into membranes, as are the measured voltage dependencies of the rate constants (Krueger et al., 1983; Moczydlowski et al., 1984; Green et al., 1987b; Guo et al., 1987). Absolute toxin affinities measured by functional blockade, interpolated to zcro mcmbranc potential, are about an order of magnitude lower than those measured by direct binding, a result stemming from a combination of higher $\left[\mathrm{Na}^{+}\right]$and higher temperature for the bilayer conditions (Weigele and Barchi, 1978a,b).

Baumgold et al. (1983) reported only a single $K_{l}(1-2 \mathrm{~nm})$ for STX binding to developing (embryonic day 19, postnatal days 5 and 42 ) rat brains that does not change during the maturation process of the neurons. However, a considerable body of information now exists delineating several sodium channel subtypes (e.g., Moczydlowski et al., 1986; Numa and Noda, 1986; Barchi, 1987; Catterall, 1988). Low-affinity STX binding sites have been reported in fetal or neonatal mouse brain (Rogart et al., 1983; Couraud et al., 1986) and cultured spinal neurons from adult guinea pig (Fukuda and Kameyama, 1980). Contrary to our observations, some low-affinity STX binding sites are TTX insensitive (Rogart, 1986).

It is notcworthy that our low-affinity binding corresponds kinetically to a slower on-rate constant with no significant difference in the dissociation rate between channel subtypes. In similar analyses of TTX-resistant $\mathrm{Na}^{+}$channels from mammalian heart and denervated muscle, the lower affinity arises from both a higher STX off-rate constant and a slower on-rate constant (Guo et al., 1987). Apparently, the low-affinity channel we describe here is kinetically distinct, and by implication, structurally different, from that found in heart and denervated skeletal muscle.

Channel blockade by the neutral STX homolog $\mathrm{Cl}$ differs distinctly from blockade by STX and dcSTX. The binding rate constant and the corresponding affinity for $\mathrm{Cl}$ are about 50100 -fold less than those parameters for the two divalent cationic toxins. This fact is consistent with the presence of negatively charged groups, fixed on the channel near the toxin binding site, which attract and concentratc positively charged toxins from the solution (Henderson et al., 1974; Hille et al., 1975; Strichartz et al., 1986). The fact that a difference in binding rate constants between GCPs and synaptosomes is apparent for STX and dcSTX yet absent for $\mathrm{C} 1 \mathrm{implies}$ that such fixed negative charges provide an essential factor in the differential toxin binding between the two membrane types. Negative charges may reside on the $\mathrm{Na}$ ' channel protein per se or on covalently bound carbohydrate, such as sialic acid (Miller et al., 1983), but are probably not 
contributed by charged phospholipids of the surrounding membrane (Green and Andersen, 1989).

Gordon et al., (1987) have shown that rat brain synaptosomes exhibit two subtypes of sodium channels, designated $R_{I}$ and $R_{I I}$, with differences in the amino acid sequence of their $\alpha$-subunits. The relative distributions of these two forms of the channel have been determined in differing parts of the brain. Developmentally, $R_{I I}$ appears first and (except in the spinal cord) is in excess of $R_{I}$ in rat brain between 0 and $90 \mathrm{~d}$ of development. A correlation of these data on channel subtypes with our observations is difficult at this time since we are not looking at a comparable developmental sequence. Instead, our analysis is confined to the growth cone and indicates a precursor-product relationship as discussed below.

\section{Channel compartmentalization and externalization}

The presence of channels in the plasmalemma and in an internal membrane compartment raises the question as to whether there is a precursor-product relationship between them in the course of plasmalemmal expansion. A considerable body of evidence has shown that neurite extension involves distal membrane insertion (Bray, 1970, 1973; Feldman et al., 1981; Pfenninger and Maylie-Pfenninger, 1981; Pfenninger, 1982; Pfenninger and Johnson, 1983). More recently, Lockerbic et al. (1991) have demonstrated that the influx of $\mathrm{Ca}^{2+}$ into intact GCPs promotes the externalization of internal binding sites of WGA to the plasmalemma. The same work has shown morphologically a concomitant reduction in internal membrane area. In the present study, the increased STX binding seen in intact GCPs following high- $\mathrm{K}^{+}$stimulation is interpreted analogously as plasmalemmal expansion by exocytosis. Whether the externalization of STX binding sites is a calcium-dependent process remains to be determined. It can be concluded that this exocytosis at the growth cone is the route of many, if not all, of the sodium channels that are destined for the plasmalemma of the extending neurite. In other words, a major path for sodium channel insertion appears to be via membrane expansion at the growth cone. At least in some cases, however, $\mathrm{Na}^{+}$channels appear on the perikaryon, for example, postaxotomy (Gilly and Brismar, 1989). Previous studies on regenerating bullfrog olfactory neurons demonstrated a decrease in STX binding sites proximodistally along the regenerating neurites, and it was proposed that lateral diffusion in the plasmalemma was the means by which sodium channels reached the advancing growth cone (Small and Pfenninger, 1984; Small et al., 1984; Strichartz et al., 1984). It now seems, however, that this may only be the mechanism for the redistribution of the channels already inserted in the perikaryon's plasmalemma.

The membrane fusion necessary for externalization of $\mathrm{Na}^{+}$ channels at the growth cone can be blocked by 1,10-phenanthroline and high levels of leupeptin, but not by aprotinin. This suggests the requirement of an active metalloendoprotease in plasmalemmal expansion and relates this process to secretion and other membrane fusion events. Proteases have been implicated in exocytosis in mast and adrenal chromaffin cells (Couch and Strittmatter, 1983, 1984; Mundy and Strittmatter, 1985) as well as the sperm acrosome reaction (Roe et al., 1988). More specifically, Mundy et al. (1987) have reported the involvement of a soluble metalloendoprotease in exocytosis in chromaffin cells. Models of the mechanism of plasmalemmal expansion will have to assign an important role to such a protease.

\section{Channel assembly and conversion}

Our observations show that, in intact and viable GCPs isolated from growing neurons in fetal brain but not manipulated further, the plasmalemma contains mostly high-affinity STX binding sites. In contrast, channels from the intracellular precursor compartment are mainly of the low-affinity type. We show further that these internal, low-affinity channels can be externalized by a quasi-physiologic stimulus, $\mathrm{K}^{+}$depolarization. However, there is an increase in both high- and low-affinity STX binding sites on the GCP surface upon high-K ${ }^{+}$stimulation. Therefore, we conclude that conversion of channels from low to high affinity must be occurring in conjunction with the plasmalemmal insertion process, at least in vivo. It is possible that the putative channel conversion is relatively slow in vivo and/or encumbered by our experimental conditions in vitro. This may account for the appearance of low-affinity STX sites not normally seen on the GCP surface.

The molecular basis of the channels' increase in STX affinity may be explained in two ways. An increase in channel sialylation would enhance binding of STX and dcSTX but not C1, as our results show. However, glycosylation concomitant with plasmalemmal insertion does not seem very likely (but will have to be tested). A sccond possibility is suggested by what is known about the $\mathrm{Na}^{+}$channel's subunit structure. Recent evidence indicates that STX binding can occur to the $\alpha$-subunit alone of the brain-derived sodium channel (Scheuer et al., 1990), without the $\beta$-subunits present (Messner and Catterall, 1986). Linkage of the $\beta_{2}$-subunit to the channel apparently occurs late in the pathway to, perhaps at, the cell surface (Schmidt and Catterall, 1986). Furthermore, the $\alpha$ - and $\beta_{2}$-subunits can be dissociated by reduction of a disulfide bond(s) (Catterall et al., 1986). Therefore, a reasonable hypothesis is that the postulated channel conversion from low to high affinity for STX is caused or accompanied by the association, and the formation of a disulfide bond(s), between the two subunits. Indeed, we have obtained preliminary evidence that $\beta$-mercaptoethanol treatment of GCP membranes converts most if not all of the plasmalemmal (highaffinity) STX binding sites to the low-affinity state. However, the two possibilitics, increase in negative charge by sialic acid versus subunit assembly, are not mutually exclusive. Because the $\beta_{2}$-subunit is glycosylated, channel oligomerization leads to an increase in sialic acid residues and thus, perhaps, toxin affinity.

We propose, therefore, that the subunits of the sodium channel pass down the developing neurite within an internal membrane compartment without association between the $\alpha$ - and $\beta_{2}$ subunits, (low-affinity STX binding site). This "pro-channel," although capable of BTX-activated $\mathrm{Na}^{+}$conductance in black lipid films, may not be fully functional in vivo by design. The formation of the disulfide-linked complex between the $\alpha$ - and $\beta_{2}$-subunits would convert it to a high-affinity STX binding conformation, characteristic of synaptosomes of the mature neuron. This would represent a final step in channel maturation or capacitation, triggered in some way by the membrane fusion event at the growth conc.

\section{References}

Ames BN, Dubin DT (1960) The role of polyamines in the neutralization of bacteriophage deoxyribonucleic acid. J Biol Chem 235: 769-775. 
Barchi RL (1987) Sodium channel diversity: subtle variations on a complex theme. Trends Neurosci 10:221-223.

Barchi RL (1988) Probing the molecular structure of the voltagedependent sodium channel. Annu Rev Neurosci 11:455-495.

Baumgold J, Zimmerman I, Bambrick L (1983) Appearance of $\left[{ }^{3} \mathrm{H}\right]$ saxitoxin binding sites in developing rat brain. Dev Brain Res 9: $405-407$.

Bennett JP (1978) Methods in binding studies. In: Neurotransmitter receptor binding (Yamamura HI, Enna SJ, Kuhar MJ, eds), pp 5790. London: Raven.

Bennett JP, Yamamura HI (1985) Neurotransmitter, hormone, or drug receptor binding methods. In: Neurotransmitter receptor binding, $2 \mathrm{~d}$ ed (Yamamura HI, Enna SJ, Kuhar MJ, eds), pp 61-89. London: Raven.

Bray D (1970) Surface movements during the growth of single explanted neurons. Proc Natl Acad Sci USA 65:905-910.

Bray D (1973) Branching patterns of individual sympathetic neurons in culture. J Cell Biol 56:702-712.

Catterall WA (1988) Structure and function of voltage-sensitive ion channels. Science 242:50-61.

Catterall WA, Morrow CS, Hartshorne RP (1979) Neurotoxin binding to receptor sites associated with voltage-sensitive sodium channels in intact, lysed and detergent-solubilized brain membranes. J Biol Chem 254:11379-11387.

Catterall WA, Schmidt JW, Messner DJ, Feller DJ (1986) Structure and biosynthesis of neuronal sodium channels. Ann NY Acad Sci 479:186-203.

Chen PS, Toribara TY, Warner H (1956) Microdetermination of phosphorus. Anal Chem 28:1756-1758.

Cheng TPO, Reese TS (1988) Compartmentalization of anterogradely and retrogradely transported organelles in axons and growth cones from chick optic tectum. J Neurosci 8:3190-3199.

Cohen RS, Blomberg F, Berzins K, Siekevitz P (1977) The structure of postsynaptic densities isolated from dog cerebral cortex. 1 . Overall morphology and protein composition. J Cell Biol 74:181-203.

Colquhoun D, Hawkes AG (1984) The principles of stochastic interpretation of ion-channel mechanisms. In: Single channel recording (Sakmann B, Neher E, eds), pp 135-175. New York: Plenum.

Couch CB, Strittmatter WJ (1983) Rat myoblast fusion requires metalloendoprotease activity. Cell 32:257-265.

Couch CB, Strittmatter WJ (1984) Specific blockers of myoblast fusion inhibit a soluble and not the membrane associated metalloendoprotease in myoblasts. J Biol Chem 259:5396-5399.

Couraud F, Martin-Moutot N, Koulakoff A, Berwald-Netter Y (1986) Neurotoxin-sensitive sodium channels in neurons developing in vivo and in vitro. J Neurosci 6:192-198.

Doyle DD, Winter A (1989) Isolation of membranes enriched in "tetrodotoxin-insensitive" saxitoxin-binding sites from mammalian ventricle. J Biol Chem 264:381 1-3817.

Feldman EL, Axelrod D, Schwartz M, Heacock AM, Agranoff BW (1981) Studies on the localization of newly added membrane in growing neurites. J Neurobiol 12:591-598.

Fukuda J, Kameyama M (1980) Tetrodotoxin-sensitive and tetrodotoxin-resistant sodium channels in tissue-cultured spinal neurons from adult mammals. Brain Res 182:191-197.

Gilly WF, Brismar T (1989) Properties of appropriately and inappropriately expressed sodium channels in squid giant axons and its somata. J Neurosci 9:1362-1374.

Gordon D, Merrick D, Auld V, Dunn R, Goldin AL, Davidson N, Catterall WA (1987) Tissue-specific expression of the $R_{I}$ and $R_{I}$ sodium channel subtypes. Proc Natl Acad Sci USA 84:8682-8686.

Green WN, Anderson OS (1989) Surface charges near the guanidinium neurotoxin binding site. Anal NY Acad Sci 479:257-268.

Green WN, Weiss LB, Andersen OS (1987a) Batrachotoxin-modified sodium channels in planar bilayers. Ion permeation and block. J Gen Physiol 89:841-842.

Green WN, Weiss LB, Andersen OS (1987b) Batrachotoxin-modified sodium channels in planar lipid bilayers. Characterization of saxitoxin- and tetrodotoxin-induced channel closures. J Gen Physiol 89: 873-904.

Guo X, Uehara A, Ravindran A, Bryant SH, Hall S, Moczydlowski E (1987) Kinetic basis for insensitivity to tetrodotoxin and saxitoxin in sodium channels of canine heart and denervated rat skeletal muscle. Biochemistry 26:7546-7556.
Hahin R, Strichartz GR (1981) Effects of deuterium oxide on the rate and dissociation constants for saxitoxin and tetrodotoxin action. $J$ Gen Physiol 78:113-139.

Hartshorne RP, Catterall WA (1981) Purification of the sodium channel from rat brain. Proc Natl Acad Sci USA 78:4620-4624.

Henderson R, Ritchie IM, Strichartz GR (1974) Fvidence that tetrodotoxin and saxitoxin act at a metal cation binding site in the sodium channels of nerve membrane. Proc Natl Acad Sci USA 71:3936-3940.

Hille B (1975) The receptor for tetrodotoxin and saxitoxin: a structural hypothesis. Biophys J 15:615-619.

Hille B, Ritchie JM, Strichartz GR (1975) The effect of surface charge on the nerve membrane on the action of tetrodotoxin and saxitoxin on frog myelinated nerve. J Physiol 250:P34-P35.

Hyman C, Pfenninger KH (1985) Intracellular regulators of neuronal sprouting: calmodulin-binding proteins of nerve growth cones. J Cell Biol 101:1153-1160.

Jones SW (1987) Sodium currents in dissociated bull-frog sympathetic neurones. J Physiol (Lond) 389:605-627.

Krueger BK, Ratzlaff RW, Strichartz GR, Blaustein MP (1979) Saxitoxin binding to synaptosomes, membranes and solubilized binding sites from rat brain. J Membr Biol 50:287-310.

Krueger BK, Worley JF, French RJ (1983) Single sodium channels from rat brain incorporated into planar lipid bilayer membranes. Nature 303:172-175.

Lockerbie RO, Miller VE, Pfenninger KH (1991) Regulated plasmalemmal expansion in nerve growth cones. J Cell Biol 112:1215-1227.

Lowry OH, Rosebrough NJ, Farr AL, Randall RJ (1951) Protein measurement with the folin phenol reagent. J Biol Chem 193:265275.

Messner DJ, Catterall WA (1985) The sodium channel from rat brain. Separation and characterization of subunits. J Biol Chem 260:1059710604.

Messner DJ, Catterall WA (1986) The sodium channel from rat brain Role of the $\beta_{1}$ and $\beta_{2}$ subunits in saxitoxin binding. J Biol Chem 261: 211-215.

Miller JA, Agnew WS, Levinson SR (1983) Principal glycopeptide of the tetrodotoxin/saxitoxin binding protcin from Electrophorus electricus: isolation and partial chemical and physical characterization. Biochemistry 22:462-470.

Moczydlowski E (1986) Single channel enzymology. In: Ion channel reconstitution (Moller C, ed), pp 75-113. New York: Plenum.

Moczydlowski E, Hall S, Garber SS, Strichartz GR, Miller C (1984) Voltage-dependent blockade of muscle $\mathrm{Na}^{+}$channels by guanidinium toxins: effect of toxin charge. J Gen Physiol 84:687-704.

Moczydlowski E, Uehara A. Guo X, Heiny J (1986) Isochannels and blocking modes of voltage-dependent sodium channels. Ann NY Acad Sci 479:269-292.

Mundy DI, Strittmatter WJ (1985) Requirement for metalloendoprotease in exocytosis: evidence in mast cells and adrenal chromaffin cells. Cell 40:645-656

Mundy DI, Hermann T, Strittmatter WJ (1987) Specific inhibitors implicate a soluble metalloendoproteinase in exocytosis. Cell Mol Neurobiol 7:425-437

Numa S, Noda M (1986) Molecular structure of the sodium channels. Ann NY Acad Sci 479:338-355.

Pfenninger KH (1982) Axonal transport in the sprouting neuron: transfer of newly synthesised membrane components to the cell surface. In: Axoplasmic transport in physiology and pathology (Weiss EG, Gorio A, eds), pp 52-61. Berlin: Springer.

Pfenninger KH, Bunge RP (1974) Freeze-fracturing of nerve growth cones and young fibers: a study of developing plasma membrane. J Cell Biol 63:180-196.

Pfenninger KH, Johnson MP (1983) Membrane biogenesis in the sprouting neuron. 1. Selective transfer of newly synthesized phospholipid into the growing neurite. J Cell Biol 97:1038-1042.

Pfenninger KH, Maylie-Pfenninger M-F (1981) Lectin labeling of sprouting neurons. II. Relative movement and appearance of glycoconjugates during plasmalemmal expansion. J Cell Biol 89:547-559.

Pfenninger KH, Ellis L, Johnson MP, Friedman LB, Somlo S (1983) Nerve growth cones isolated from fetal rat brain: subcellular fractionation and characterization. Cell 35:573-584.

Pfenninger $\mathrm{KH}$, de la Houssaye BA, Frame L, Helmke S, Lockerbie RO, Lohse K, Miller V, Negre-Aminou P, Wood MR (1992) Biochemical dissection of plasmalemmal expansion at the growth cone. 
In: The nerve growth cone (Letourneau PC, Kater SB, Macagno ER, eds), pp 111-123. New York: Raven.

Roe JL, Farach HA Jr, Strittmatter WJ, Lennarz WJ (1988) Evidence for the involvement of metalloendoproteases in a step in sea urchin gamete fusion. J Cell Biol 107:539-544.

Rogart RB (1986) High-STX-affinity vs. low-STX-affinity $\mathrm{Na}^{+}$channel subtypes in nerve, heart, and skeletal muscle. Ann NY Acad Sci 479:402-430.

Rogart RB, Willinger M, Kusma G (1983) Expression of excitable sodium channels in developing mouse cerebellum. Soc Neurosci Abstr 9:504.

Scheinman RI, Auld VJ, Goldin AL, Davidson N, Dunn RJ, Catterall WA (1989) Developmental regulation of sodium channel expression in the rat forebrain. J Biol Chem 264:10660-10666.

Scheuer T, Auld VJ, Boyd S, Offord J, Dunn R, Cattcrall WA (1990) Functional properties of rat brain sodium channels expressed in a somatic cell line. Science 247:854-858.

Schmidt JW, Catterall WA (1986) Biosynthesis and processing of the $\alpha$-subunit of the voltage-sensitive sodium channel in rat brain neurons. Cell $46: 437-445$.

Schmidt JW, Rossie S, Catterall WA (1985) A large intracellular pool of inactive $\mathrm{Na}^{+}$channel $\alpha$-subunits in developing rat brain. Proc Natl Acad Sci USA 82:4847-4851.

Small RK, Pfenninger KH (1984) Components of the plasma membrane of growing axons. I. Size and distribution of intramembrane particles. J Cell Biol 98:1422-1433.

Small RK, Blank M, Ghez R, Pfenninger KH (1984) Components of the plasma membrane of growing axons. II. Diffusion of membrane protein complexes. J Cell Biol 98:1434-1443.

Strichartz GR, Small RK, Pfenninger KH (1984) Components of the plasma membrane. III. Saxitoxin binding to sodium channels. J Cell Biol 98:1444-1452.
Strichartz G, Rando T, Hall S, Gitschier J, Hall L, Magnani B, Bay CH (1986) On the mechanism by which saxitoxin binds to and blocks sodium channels. Ann NY Acad Sci 479:96-112.

Wagner H-H, Ulbricht W (1975) The rates of saxitoxin action and of saxitoxin-tetrodotoxin interaction at the node of Ranvier. Pfluegers Arch 359:297-315.

Weigele JB, Barchi RL (1978a) Analysis of saxitoxin binding in isolated rat synaptosomes using a rapid filtration assay. FEBS Lett 91: 310-314.

Weigele JB, Barchi RL (1978b) Saxitoxin binding to the mammalian sodium channel: competition by monovalent and divalent cations. FEBS Lett 95:49-53.

Weiss RE, Horn R (1986a) Single-channel studies of TTX-sensitive and TTX-resistant sodium channels in developing rat muscle reveal different open channel properties. Ann NY Acad Sci 479:152-161.

Weiss RE, Horn R (1986b) Functional differences between two classes of sodium channels in developing rat skeletal muscle. Science 233 361-364.

White $C$ (1952) The use of ranks in a test of significance for comparing two treatments. Biometrics 8:33-41.

Wollner DA, Scheinman R, Catterall WA (1988) Sodium channel expression and assembly during development of retinal ganglion cells. Neuron 1:727-737.

Wood MR, May N, Strichartz G, Pfenninger KH (1987) Two types of sodium channel in growth cone membranes. J Cell Biol 105:143a.

Wood MR, Strichartz G, Elmer L, Angelides K, Pfenninger KH (1988) $\mathrm{Na}^{+}$channels in differentiating neurons. Soc Neurosci Abstr 14:834.

Wood MR, Strichartz G, Pfenninger KH (1989) Compartmentalization of $\mathrm{Na}^{+}$channels in nerve growth cones: channel conversion during plasmalemmal insertion? J Cell Biol 109:335a. 